\title{
STRUCTURAL HEALTH MONITORING OF BRIDGES USING ADVANCED NON-DESTRUCTIVE TESTING TECHNIQUE
}

\author{
MAIZUAR MAIZUAR ${ }^{1,2}$, L. ZHANG ${ }^{1, *}$, SAEED MIRAMINI ${ }^{1}$, PRIYAN MENDIS ${ }^{1}$, \\ COLLIN DUFFIELD ${ }^{1}$
}

\author{
${ }^{1}$ Department of Infrastructure Engineering, the University of Melbourne, VIC 3010, Australia \\ ${ }^{2}$ Department of Civil Engineering, Malikussaleh University, Indonesia \\ *Corresponding author: lihzhang@unimelb.edu.au
}

\begin{abstract}
This paper presents an integrated framework for structural health monitoring of bridges by using advanced non-destructive testing (NDT) technique in conjunction with computational modelling. First, the structural characteristics of the Eltham Trestle Bridge under train loading were monitored using the combination of the 3D optical measurement system and IBIS-S. The results demonstrate that, in conjunction with computational modelling, the NDT can capture the structural health conditions of the bridge by analysing the natural frequencies and deformation profiles of the critical members of the bridges. Then, the developed framework also takes into account the impact of extreme events (e.g. truck impacts and earthquakes) by using a reliability-based model. Finally, using the Montague Street Bridge as a case study, it shows that proposed framework has the capability of predicting the residual life of a bridge subject to both progressive deterioration and extreme events throughout its service life.
\end{abstract}

Keywords: structural monitoring; bridge; IBIS-S; ARAMIS; NDT technique; FE modelling; reliability

\section{INTRODUCTION}

The structural deterioration related to ageing bridges with the increased demand of heavy traffic loads has severe consequences for the safety of human life and properties (Biondini and Frangopol 2016, Davalos 2012). For example, catastrophic collapse of bridge over the Mississippi River in Minneapolis, USA, on $1^{\text {st }}$ August 2007, has sparked global attention in the structural deficiencies of the infrastructure. This event caused the death of thirteen people and 145 people were injured, as well as trillions dollars of capital losses (French et al. 2011, Hao 2010, Salem and Helmy 2014). In Australia, it is estimated the number of bridges is approximately 50.000 with majority of them being over 50 years old indicating that many of bridges may be deteriorating due to the ageing process (Atkins 1991, Rashidi and Lemass 2011).

Bridges are generally characterized by their growing deterioration rate as a result of progressive deterioration caused mainly by heavy traffic condition and sudden extreme events (e.g., truck impact). Heavy freight transport has rapidly risen in past decades. In Australia, the total domestic road freight has grown six-fold over the last four decades, from around 27 billion ton kilometers in 1971 to over 180 billion ton kilometers in 2007 (BITRE 2011). Further, the recent economic projection for the freight task will be nearly double between 2010 and 2030 in line with the economic growth and triple by 2050, and increase by about 
$26 \%$ by 2026 (Richards 2014). The implication of these projections is that the number of articulated truck movements required to undertake the freight task would increase dramatically. Ageing bridge infrastructures as well as the increase traffic loads from articulated trucks could considerably affect the accelerating rate of the structural deterioration of bridges and ultimately the reduced service life of bridge structures (Kafle et al. 2017, Maizuar et al. 2017, Zhang et al. 2016a, Zhang et al. 2016b). As conventional methods for structural monitoring of bridges may have limitation in detecting some types of bridge damage, the development of an innovative structural monitoring technique of bridges is of paramount important.

Residual life prediction of bridges involves estimation of the progressive damage accumulation due to ageing bridge and the immediate damage caused by extreme events (e.g. truck impact). This problem is not fully understood yet. Further, very limited research and literature can be found where the effect of the increased heavy traffic on the residual life of bridges has been reported. In response to this context, a reliability-based life-cycle assessment framework to estimate the cumulated damage of progressive deterioration and sudden extreme events caused by truck impacts has been developed in this study.

\section{ADVANCED NON-DESTRUCTIVE TESTING (NDT) TECHNIQUE}

\subsection{IBIS-S Interferometric Radar Technology}

The IBIS-S uses interferometry technique to measure the line-of-sight (radial) displacement $\left(d_{r}\right)$ of all the reflectors on the structure that are more than $0.5 \mathrm{~m}$ apart. By assuming that $\Delta \theta$ is the phase shift of the electromagnetic waves reflected by the object in various time intervals and $\lambda$ is the wavelength of the electromagnetic signal, the radial displacement $\left(d_{r}\right)$ is given by,

$$
d_{r}=\frac{\lambda}{4 \pi} \Delta \theta
$$

Once the radial displacement has been obtained, the actual displacement of the measured points can be easily calculated by applying a simple geometric projection. In addition, the IBIS-S also uses SF-CW technique in detecting the position of different target points placed along the route of the line-of-sight of radar measurement. This technique enables to determine the range resolution $(\Delta R)$ using the short time duration $(\tau)$ pulses which can be expressed as,

$$
\Delta R=\frac{c \tau}{2}
$$

Where, $c$ is speed of light in free space and $\tau=1 / B$. The SF-CW technique is based on transmission of a burst of $N$ monochromatic pulses with identical, and increasing frequency (e.g., with set frequency step of $\Delta f$ ) rather than transmitting a short time pulse duration with a large bandwidth in frequency domain to attain a large effective bandwidth $B$ :

$$
B=(N-1) \Delta f
$$

In order to obtain unambiguous radar target, the range of the targets should be closer than the maximum measured distance $\left(R_{\max }\right)$, which is given by,

$$
R_{\max }=\frac{c}{2 \Delta f}
$$

Thus, the maximum sampling rate $\left(f_{\max }\right)$ can be obtained by substituting Equation 2 and Equation 3 into Equation 4 as follows,

$$
f_{\max }=\frac{c \Delta R}{4 R_{\max }^{2}}
$$

\subsection{ARAMIS 3D Optical Measurement System}

A typical of ARAMIS components which primarily consists of two high speed digital 
cameras, specimen lightings, laser pointer, tripod, data acquisition unit and a processing unit installed with ARAMIS software package. The images of an object from different angles were captured by the digital CCD cameras and the time-dependent deformation of the object is obtained through image processing using ARAMIS post-processing software.

ARAMIS uses the advanced of photogrammetry technique. Photogrammetry is based on the optical measurement to generate 3D-coordinates of surface points (Tworzewski and Goszczynska 2016). This method allows capturing and estimating of the relative positions changes of two images on the surface of the object. The 3D surface displacements and strain can be calculated from the data when the object is deformed.

\section{STRUCTURAL HEALTH MONITORING OF BRIDGES}

The objective of this experimental test is to present an integrated framework for structural monitoring of the Eltham rail trestle by using IBIS-S and ARAMIS system under train loading. The Eltham Bridge is a unique and valuable historic timber bridge in Australia that is still providing train service for Melbourne's metropolitan electric railway network. Built in 1902 , this timber bridge has a length of approximately $200 \mathrm{~m}$ and is possibly the longest curved wooden bridge for commuter railway in the southern hemisphere (Chambers et al. 1998, VHD 2005).

In this test, the IBIS-S radar sensors were pointed out to cover a horizontal distance of $5.2 \mathrm{~m}$ and a height $(h)$ of $3 \mathrm{~m}$ with a distance resolution of $0.75 \mathrm{~m}$ and a sampling frequency of $100 \mathrm{~Hz}$. Simultaneously, the deformation of the timber column measured by ARAMIS was approximately $1.5 \mathrm{~m}$ above ground level with camera lens distance of $810 \mathrm{~mm}$ from the measurement surface and measurement area of $100 \times 75 \mathrm{~mm}$ (Figure 1).

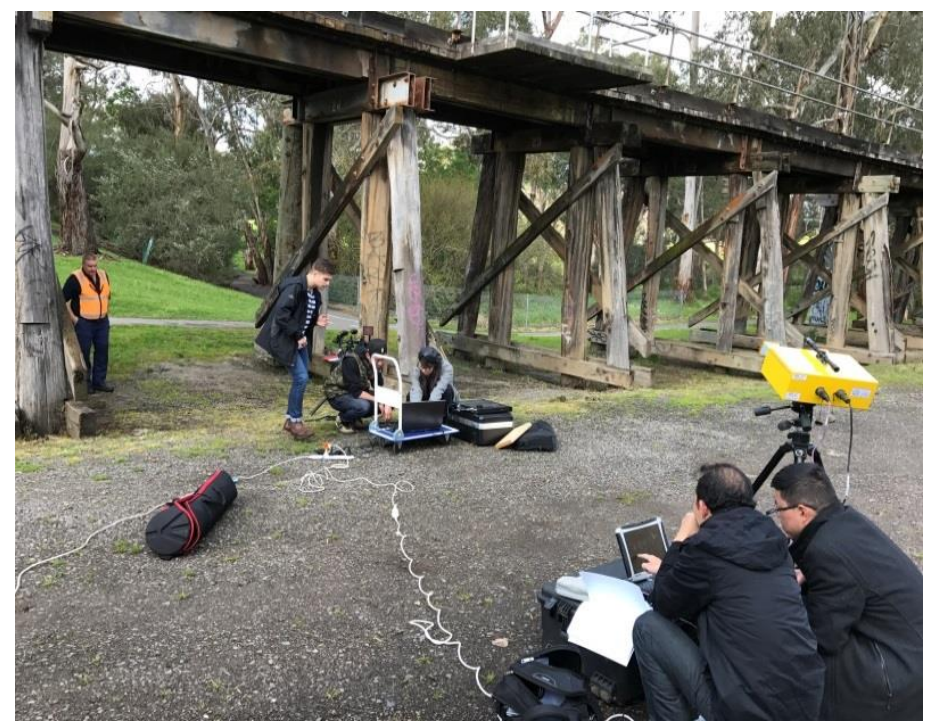

Figure 1 Structural monitoring of the bridge using IBIS-S and ARAMIS

A three-dimensional FE model of the bridge was developed using FE simulation software ANSYS 14.5 to validate both IBIS-S and ARAMIS measurements (Figure 2). The 3D solid elements were used for modelling all structural members of the bridge. The piers were considered to be fixed supports and displacements and rotations were assigned to the girder ends. 


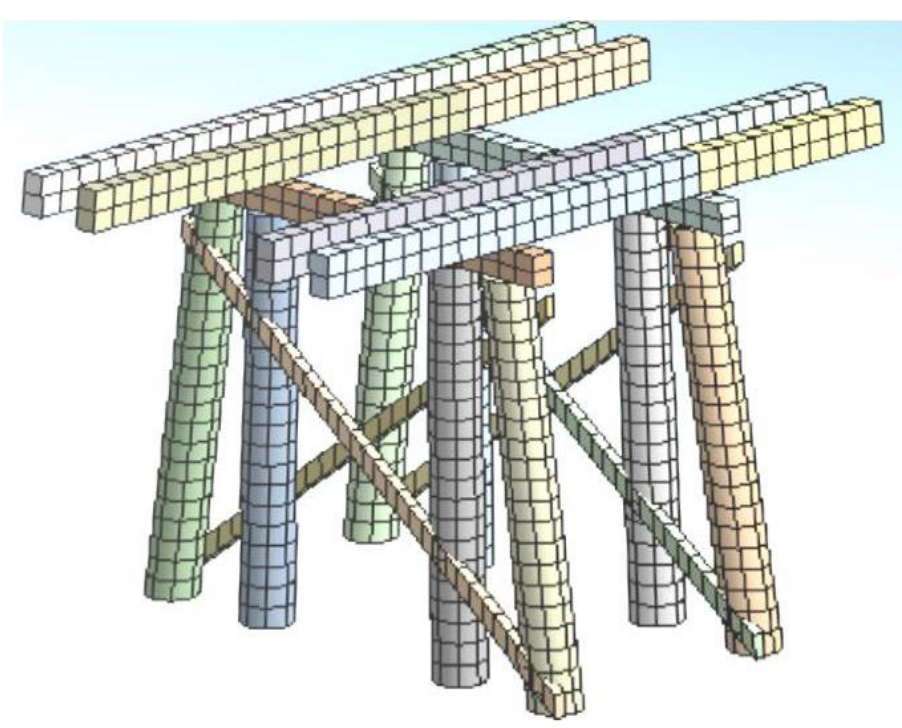

Figure 2 3D FE model of the bridge

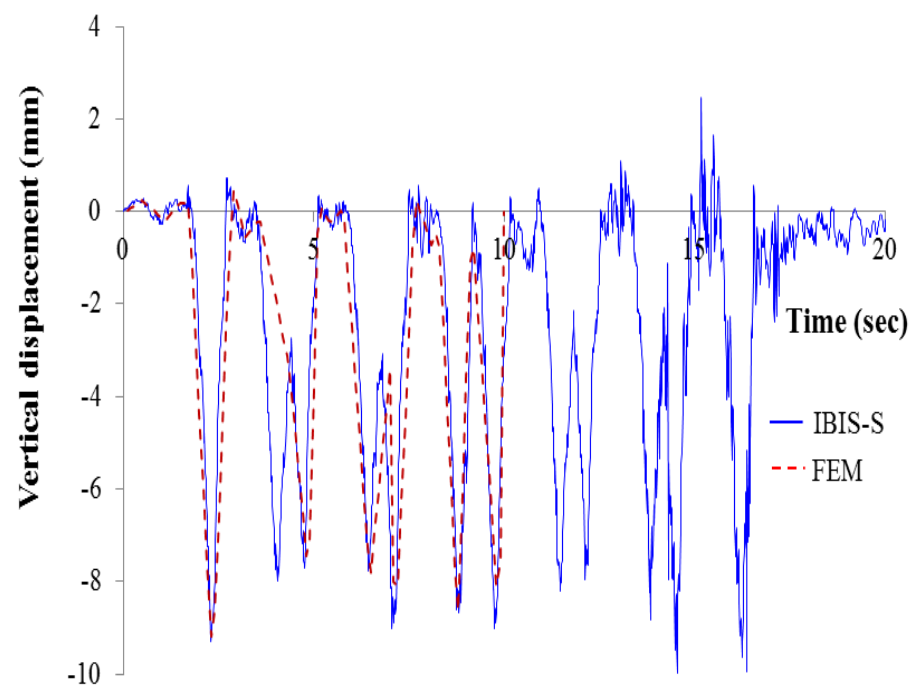

Figure 3 Comparison vertical displacement of bridge girder measured by IBIS-S with that from FEM prediction

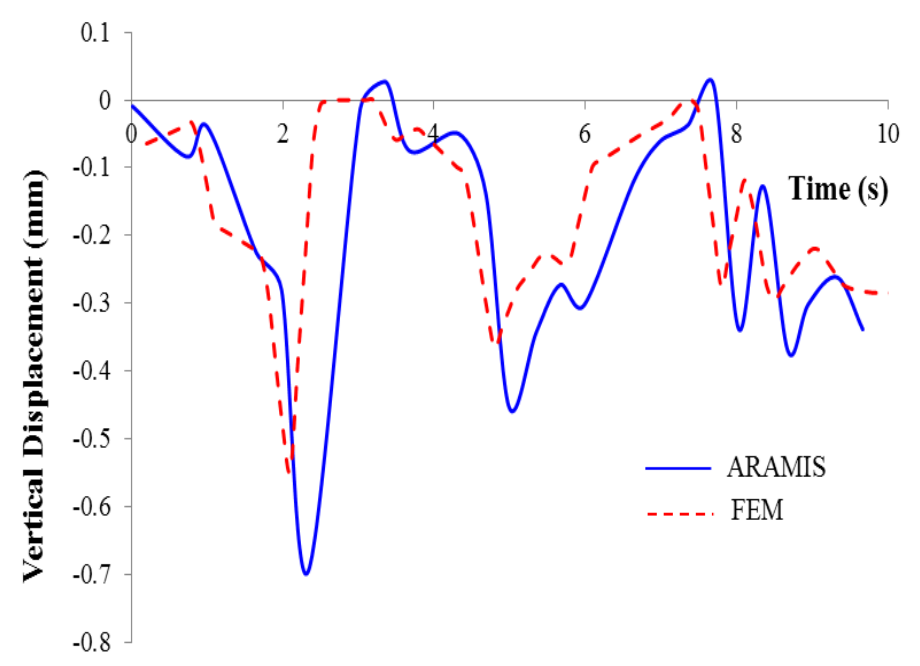

Figure 4 Comparison of deformation of the bridge column measured by ARAMIS with that from FEM predictions 
The comparison of vertical displacement obtained from experimental tests using IBIS-S with that from FE modelling is shown in Figure 3. It can be seen in Figure 3 that the timedependent displacement of the bridge girder from FE model matches very well with that from IBIS-S experimental data.

The time-dependent deformation of timber bridge column measured by ARAMIS and FE model results is shown in Figure 4. It was found that FE results are very close to ARAMIS experimental data. Further, the natural frequencies of the bridge obtained from IBIS-S and FE model are shown in Table 1 . It can be seen that the FE modelling results exhibit reasonably well with that from IBIS-S experimental data.

Table 1 Comparison of frequencies obtained from experiment and FE modelling

\begin{tabular}{|c|c|}
\hline \multicolumn{2}{|c|}{ Natural frequency $\mathbf{( H z )}$} \\
\hline IBIS-S measurement & FE modelling \\
\hline 4.5 & 4.1 \\
\hline
\end{tabular}

\section{RELIABILITY ANALYSIS OF THE LIFE-CYCLE PERFORMANCE OF BRIDGES}

Structural degradation of bridges is characterized by the accumulation damage as a result of progressive deterioration and shocks caused by extreme event (Figure 5). Assuming that both shock degradation and progressive deterioration are independent, the damage accumulation $D_{W}(t)$ can be obtained as,

$$
D_{W}(t)=\sum_{i=0}^{N} U_{i}+\sum_{i=0}^{N} V_{i}
$$

Where, $U_{i}$ is the loss of structural capacity (damage size) caused by a shock and $V_{i}$ is the discrete changes in structural system described by a series of fictitious shocks occurring at a certain fix time interval. When the combined deterioration is considered, the loss of structural capacity of a bridge $C_{W}$ can be expressed as,

$$
C_{W}(t)=C_{0}-\left(\sum_{i=0}^{N} U_{i}+\sum_{i=0}^{N} V_{i}\right)-a^{*}
$$

Where, $a^{*}$ is the threshold limit value and $C_{0}$ is the initial capacity of structures. Then, the probability of failure of the structure $P_{W}$ can be obtained by assuming that $V_{W}(t)$ follows distribution of $G_{W}$,

$$
P_{W}=1-\int_{0}^{C_{W}(t)} G_{W}(y) d y
$$

The numerical procedure using MATLAB program to compute probability of failure was implemented to Montague Bridge Victoria, Australia. In this simulation, the initial capacity of the bridge $C_{0}$ is $100 \%$ with a threshold limit $s^{*}$ of $25 \%$. Both loss of structural capacity (damage size) caused by shocks (e.g., truck impacts) and the inter-arrival time between shocks were assumed exponentially distributed with $U_{i}$ of $2 \%$ and $\mu$ of 1.5 years. For progressive deterioration, the size of every jump is also considered exponentially distributed with an average rate $V_{i}$ of $0.75 \%$. Assume further that the damage caused by shocks and progressive deterioration follows exponential distribution $G(y, \theta)$ with an average rate $\theta$ of 0.05 . 


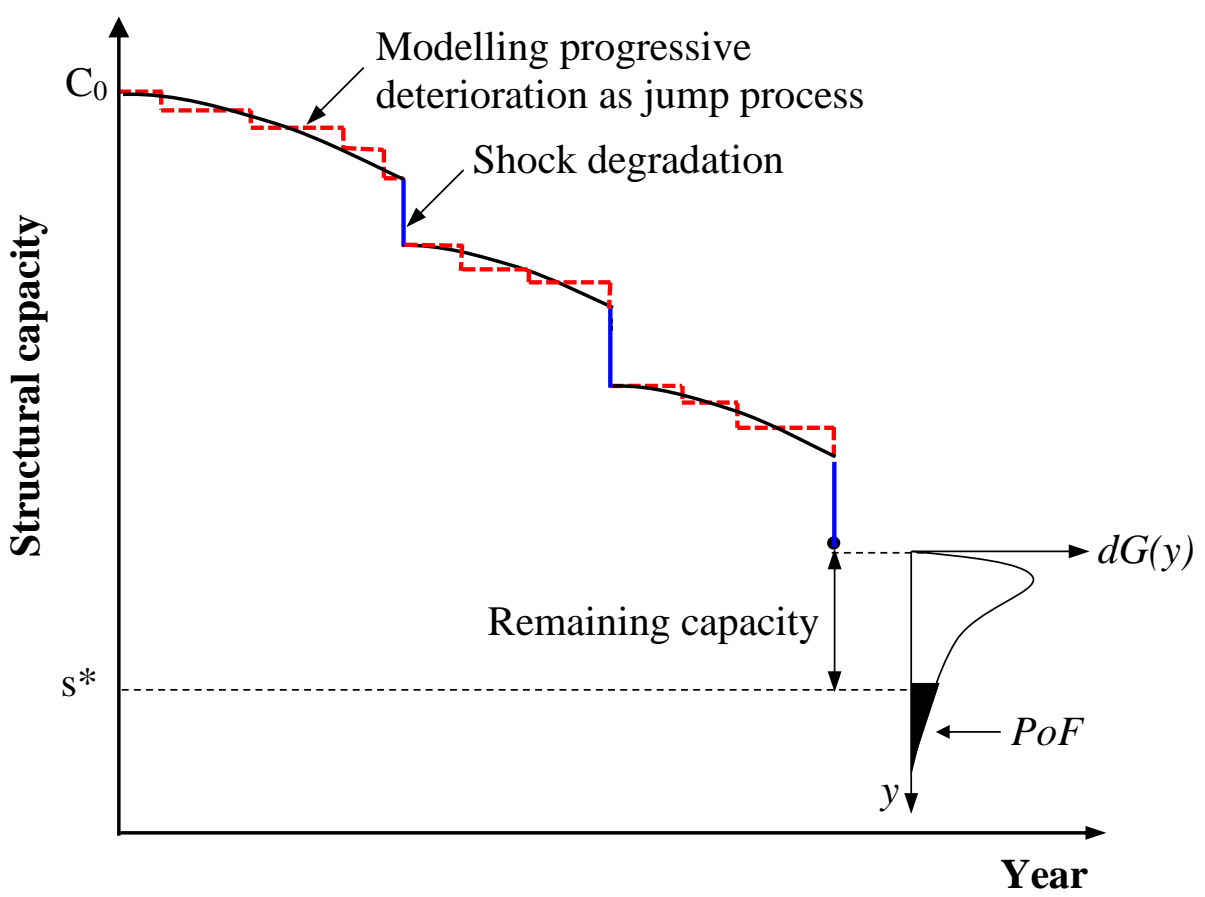

Figure 5 Modelling structural deterioration caused by shock and progressive deterioration

(a)

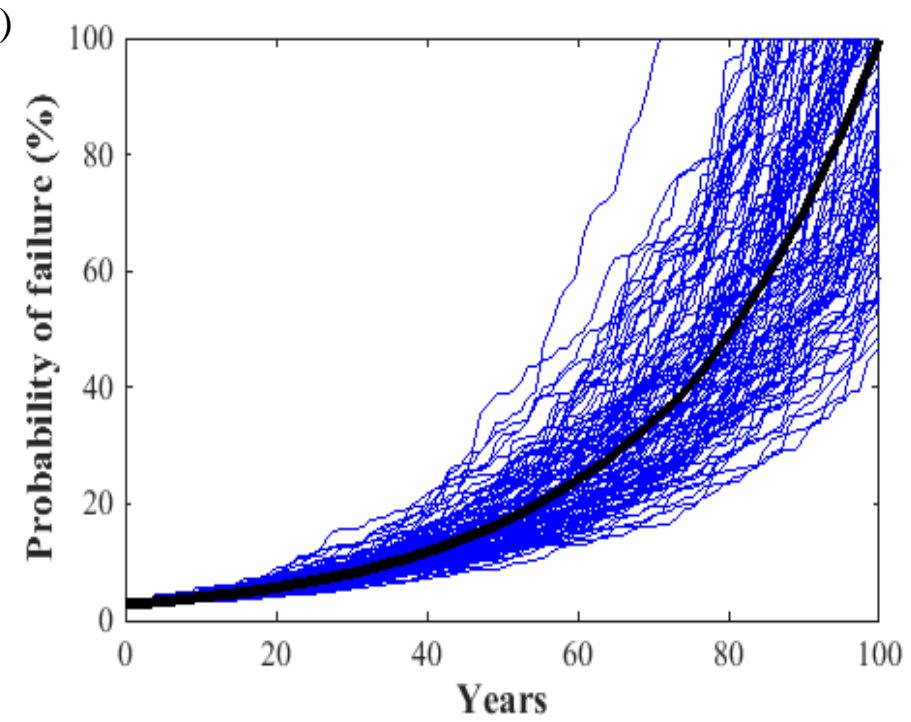

(b)

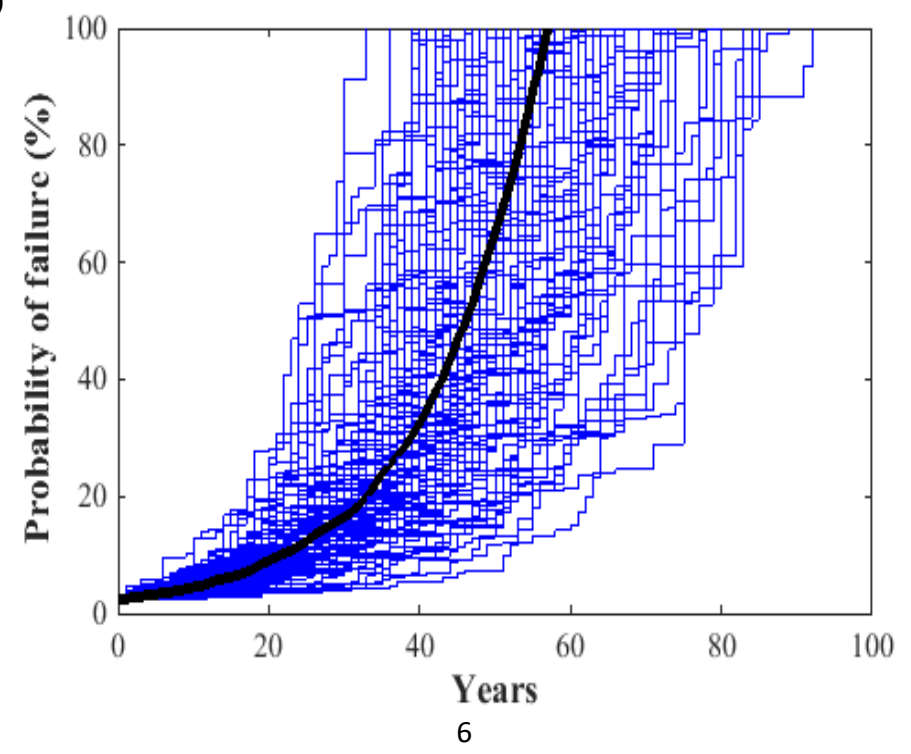


(c)

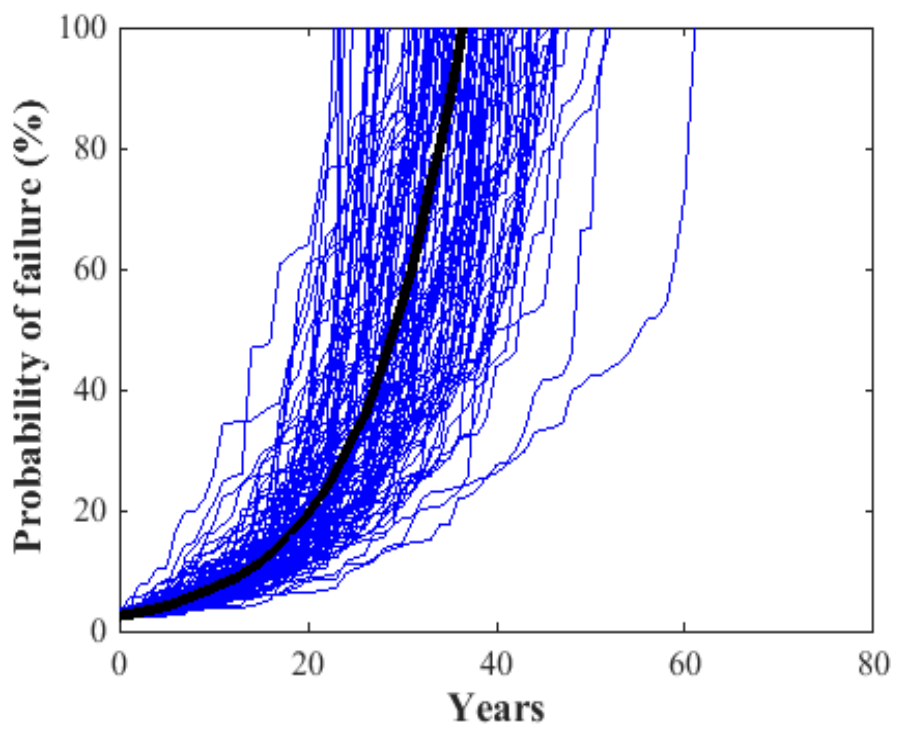

Figure 6 Plot of random sample paths showing probability of failure of the bridge as a result of (a) progressive deterioration only (b) shock only (c) combination of both.

The random sample paths showing the probability of the bridge under progressive deterioration, shock degradation and the combination of both are presented in Figure 6. As shown in Figure 6, the average deterioration was used to compute the probability of failure of the bridge marked by black line. It can be seen that the bridge lifespan under progressive deterioration, truck impact, and the combination of both are 100 years, 57 years and 35 years, respectively. The simulation results indicate that the impact of progressive deterioration and shocks by extreme event (e.g., truck impacts) has significant effect on the decrease of residual life of bridges.

\section{CONCLUSIONS}

An integrated framework for structural health monitoring of bridges by using advanced non-destructive testing (NDT) technique in conjunction with computational modelling was presented. Using bridges in Australia as case studies, the application of the recent advance NDT technique for remote structural vibration and deformation (e.g., IBIS-S and ARAMIS system) has been successfully performed. The FE models were then developed to validate the NDT measurements results. The outcomes of the study demonstrate that NDT can capture the structural health conditions of the bridges by analysing the natural frequencies and deformation profiles of the critical members of the bridges. Further, the developed framework by using a reliability-based model has the capability of predicting the residual life of a bridge subject to both progressive deterioration and multiple truck impacts throughout its lifespan.

\section{ACKNOWLEDGEMENTS}

The authors wish to thank the Australian Research Council (ARC IH150100006), Australia-Indonesia Centre (TRP 2016), Bushfire and Natural Hazards CRC. 


\section{REFERENCES}

Atkins, R. M. (1991), National bridge performance indicator for Austroads bridge management system. Brisbane Australia.

Biondini, F., Frangopol, D. M. (2016), Life-cycle performance of deteriorating structural systems under uncertainty: Review, Journal of Structural Engineering, 142(9), 1-17.

BITRE (2011). Truck productivity: sources, trends and future prospects: Report 123. Canberra, Australia:

Chambers, D., Churchward, M., McInnes, K., Moloney, D. (1998), Victoria's timber bridges, Proceedings of 9th National Conference on Engineering Heritage, 1998, 37-47.

Davalos, J. F. (2012), Advanced materials for civil infrastructure rehabilitation and protection, Proceedings of Seminar at The City College of New York, New York, 2012,

French, C. E., Hedegaard, B., Shield, C. K., Stolarski, H. (2011), I35W collapse, rebuild, and structural health monitoring - Challenges associated with structural health monitoring of bridge systems, Proceedings of AIP Conference Proceedings, 2011, 9-30.

Hao, S. (2010), I-35W Bridge Collapse, Journal of Bridge Engineering, 15(5), 608-614.

Kafle, B., Zhang, L., Mendis, P., Maizuar, M., Duffield, C., Thompson, R. (2017), Monitor the dynamic behaviour of the Merlynston Creek Bridge using interferometric radar sensors and finite element modelling, International Journal of Applied Mechanics, 9(1), 1750003-1750023.

Maizuar, M., Zhang, L., Miramini, S., Mendis, P., Thompson, R. G. (2017), Detecting structural damage to bridge girders using radar interferometry and computational modelling, Struct Control Health Monit, 24(10), 1-6.

Rashidi, M., Lemass, B. (2011), A decision support methodology for remediation planning of concrete bridges, Journal of construction engineering and project management, 1(2), 1-10.

Richards, B. (2014).Transport and logistics insights: The road ahead. www.ferrierhodgson.com; 2014 [accessed 18.08.2017]

Salem, H. M., Helmy, H. M. (2014), Numerical investigation of collapse of the Minnesota I-35W bridge, Engineering Structures, 59, 635-645.

Tworzewski, P., Goszczynska, B. (2016), An application of an optical measuring system to reinforced concrete beams analysis, Proceedings of 2016 Prognostics and System Health Management Conference (PHM-Chengdu), 2016, 1-6.

VHD (2005).Eltham rail trestle bridge. http://vhd.heritagecouncil.vic.gov.au/places/66300; 2005 [accessed 25.05.2017]

Zhang, L., Maizuar, M., Mendis, P., Duffield, C., Thompson, R. G. (2016a), Monitoring the dynamic behaviour of concrete bridges using non-contact sensors (IBIS-S), Applied Mechanics \& Materials, 846, 225-230.

Zhang, L., Thompson, R. G., Maizuar, M. (2016b), An innovative condition assessment approach for concrete bridges under heavy truck loads, Paper presented at the 27th ARRB Conference, Melbourne, Australia. 


\section{University Library}

\section{- M M I N E R VA A gateway to Melbourne's research publications}

Minerva Access is the Institutional Repository of The University of Melbourne

Author/s:

Maizuar, M;Zhang, L;Miramini, S;Mendis, P;Duffield, C

Title:

Structural Health Monitoring of Bridges Using Advanced Non-destructive Testing Technique

Date:

2020-01-01

Citation:

Maizuar, M., Zhang, L., Miramini, S., Mendis, P. \& Duffield, C. (2020). Structural Health

Monitoring of Bridges Using Advanced Non-destructive Testing Technique. Wang, CM (Ed.). Ho, JCM (Ed.). Kitipornchai, S (Ed.). ACMSM25, (1), pp.963-972. Springer, Singapore.

Persistent Link:

http://hdl.handle.net/11343/292051 